\title{
EVALUATION OF SEMINAL IGF-1 AND A2-MACROGLOBULIN MEASUREMENT IN PREDICTING TESTICULAR SPERM OUTPUT
}

\author{
Authors: Ahmed Ibrahim Rasheed* (1), Nermeen Samy Abdelfattah* (1), Dina El \\ Sayed El Shennawy** (2).
}

Department of Dermatology and, Department of Clinical Pathology Faculty of Medicine, Ain Shams University, Cairo, Egypt

\section{Corresponds:}

Ahmed Sayed Youssef. Ali e.male:

dr ahmed derma@yahoo.com Tel.: 01146212134

Receved: $18 / 2 / 2019$

Accepted: 20/3/2019

\section{ABSTRACT}

Background: Partial obstruction is roughly defined as the presence of oligozoospermia with normal or nearly normal sperm production in the seminiferous tubules. The obstruction can occur at any site along the male genital tract. Broadly speaking, diagnosis of obstructive oligozoospermia could be suggested by some findings in history (e.g. of trauma or infection), in examination\&/or investigations (e.g. epididymal swelling or marked discrepancy between testicular size and previous sperm counts) but most strongly, by the lack of correlation between score of mature spermatids $(S c+d)$ in the testicular biopsy and the sperm concentration in the semen analysis.

Aim of work: To evaluate the relation between the levels of IGF1 and 22-macroglobulinin predicting testicular sperm output of the testicles as judged from quantitative analysis of testicular biopsy in oligozoospermic cases.

Patients and methods: 40 oligozoospermic patients were subjected to full history taking, complete general and local examinations, scrotal duplex, semen analysis, blood chemistry, hormonal profile, bilateral open testicular biopsies and measurement of seminal IGF-1 and $\alpha_{2}$-macroglobulin.

Results: Patients are divided into 2 groups; group I with likely or partial obstruction and group II with unlikely or no obstruction. There is a lack of correlation between IGF-1 \& $\alpha_{2}$-macroglobulin and expected sperm count (from quantitative testicular biopsy) in both groups.

Conclusion: IGF-1 \& $\alpha_{2}$-macroglobulin are not reliable markers for partial obstruction of the male genital system.

Keywords: obstructive oligozoospermia, Partial obstruction

\section{INTRODUCTION:}

Oligozoospermia is most commonly considered to be the result of deficient spermatogenesis. Nevertheless, the existence of obstructive oligozoospermia "whether partial or unilateral" must be always put in mind ${ }^{(1)}$. Owing to the difficulty inherent in diagnosing such cases, their exact incidence is somewhat difficult to ascertain ${ }^{(2)}$. Partial obstruction is roughly defined as the presence of oligozoospermia with normal or nearly normal sperm production in the seminiferous tubules ${ }^{(1)}$. The obstruction can occur at any site along the male genital tract. Broadly speaking, diagnosis of obstructive oligozoospermia could be suggested by some findings in history (e.g. of trauma or infection), in examination \&/or investigations (e.g. epididymal swelling or marked discrepancy between testicular size and previous sperm counts) ${ }^{(3)}$ but most strongly, by the lack of correlation between score of 
mature spermatids $(\mathrm{Sc}+\mathrm{d})$ in the testicular biopsy and the sperm concentration in the semen analysis ${ }^{(4)}$. The frequency of obstructtive oligozoospermia is roughly estimated to be as high as $20 \%$ among patients with sperm concentrations of less than 5 million sperm $/ \mathrm{ml}^{(5)}$ and about $10 \%$ among patients with sperm concentrations of less than 10 million sperm $/ \mathrm{ml}^{(4)}$. Spermatogenesis is a complex developmental process that depends primarily on pituitary gonadotrophins and testosterone. These hormones exert an indirect effect on spermatogenetic cells through locally produced autocrine, paracrine and juxtacrine factors. These factors -in turn- have been shown to mediate complex interactions between Leydig cells, peritubular myoid cells, Sertoli cells and spermatogenetic cells as a prerequisite of maintenance and control of spermatogenesis. However, the exact physiological role of many of these factors in the testis remain to be clearly delineated ${ }^{(6)}$.Testicular IGF-I is mainly produced in Sertoli cells under the stimulation of $\mathrm{FSH}^{(7)}$. Seminal IGF-1 concentrations have been shown to be significantly correlated with the percentage of morphologically normal spermatozoa and sperm concentration. It is also found that the concentration of IGF-1 is reduced in seminal plasma after vasectomy ${ }^{(6)}$. On the other hand, alpha $a_{2}$-macroglobulin $\left(\alpha_{2}-\mathrm{M}\right)$ is a high-molecular-weight tetrameric protein. It is also synthesized in Sertoli cells under the control of $\mathrm{FSH}^{(8)}$. Total $\alpha 2$ macroglobulin in seminal plasma has been also shown to be significantly correlated with the sperm count and percentage of progressively motile spermatozoa. They concluded that the concentrations of both IGF-1 and $\alpha_{2}$ macroglobulin in human seminal plasma were correlated to semen quality, basal concentrations of $\mathrm{HGH}$, testosterone, IGFBP-3, soluble fibronectin receptor (sFNR), PSA and pp14 in seminal plasma as well as to serum concentrations of $\mathrm{LH}$ and $\mathrm{FSH}^{(6)}$. Testicular biopsy is most commonly examined by the clinicians in a descriptive, non quantitative way. This has severely limited its usefulness and led to many errors in its interpretation ${ }^{(9)}$. For that same reason, testicular biopsy has not found much use in men with oligozoospermia ${ }^{(10)}$. The number of mature spermatids in a minimum of 20 tubules were simply counted and divided by the number of tubules. The number of mature spermatids per tubule correlated very closely to the sperm count per milliliter. The equation given was $\mathrm{y}=\mathrm{a}(\mathrm{x})^{\mathrm{b}}$ where $\mathrm{x}$ is the expected sperm count in million/ $\mathrm{ml}$, $\mathrm{a}$ and $\mathrm{b}$ are two constants equal to 10.39 and 0.31 respectively and $\mathrm{y}$ is the number of late spermatids/tubule. By this method, cases of partial obstruction can be diagnosed if there is a high discrepancy between the late spermatid score and the sperm count ${ }^{(4)}$.

\section{AIM OF WORK:}

To evaluate the relation between the levels of IGF-1 and $\alpha 2$-macroglobulinin predicting testicular sperm output of the testicles as judged from quantitative analysis of testicular biopsy in oligozoospermic cases.

\section{PATIENTS AND METHODS:}

This study includes 40 oligozoospermic patients whose sperm counts are below 10 million sperm $/ \mathrm{ml}$ and ages range from 35-55 years. They were collected from the Andrology Outpatient Clinic - Ain Shams University Hospitals during the period from July 2014 till March 2018. Excluded from the study were patients with azoospermia or with sperm count more than 10 million $/ \mathrm{ml}$, any patient with significant demonstrable factor(s) that would affect spermatogenesis, patients with significant associated defects in the seminogram, patients with significant reduction in the testicular size or consistency and patient's less than 35 years or more than 55 years old. Written informed consent, full history taking, complete general and local examinations, scrotal duplex, prostatic 
discharge examination, hormonal profile: including S.FSH, S.LH, S.prolactin and S.testosterone (total and free). A scrotal duplex US was performed in both supine and standing positions. A high frequency US transducer (above $7 \mathrm{MHz}$ ) was utilized with a penetration depth of the ultrasound beam ranging from $3-5 \mathrm{~cm}$ to precisely evaluate the entire scrotal and inguinal canal contents. It was performed after elevation of the testes with a towel underneath the scrotum. A side-by-side protocol with large field of view image including both testes using the grayscale and color Doppler techniques was performed to allow the comparison of the testicular echogenicity and perfusion on both sides. Then, longitudinal images for each testis (in the medial, mid and lateral positions) and transverse images (of the upper, mid and lower pole) were obtained. Each testis was measured consecutively in three dimensions (length, height and width). Using the available US calculation software, testicular volume was detected for each side. Evaluation of both epididymi was performed for any dilatation denoting distal obstruction (after 3 days of sexual abstinence). It included longitudinal and transverse images for head, body and tail as well as imaging for any cystic swellings in its portions. Veins of pampiniform plexus were specifically evaluated for their diameter and augmentation with Valsalva maneuver while the patient was in the upright position with special attention to the reflux. Each patient provided a semen sample after 3 days of sexual abstinence by masturbation. The semen sample was freshly collected into a sterile wide-mouthed clean polypropylene plastic container without using a lubricant or soap. After liquefaction, semen was routinely microscopically examined for concentration per milliliter, motility and abnormal forms. Then, Cell-free seminal plasma was obtained after an initial centrifugation (1000 g for 10 minutes) followed by an additional centrifugation of the supernatant (4000 $\mathrm{g}$ for 20 minutes) to remove the debris. Microscopic examination was performed again to ensure that the seminal plasma was sperm-free. Seminal plasma aliquots were stored at $-20 \square$ until assay of IGF-1 and $\alpha_{2}$-macroglobulin (see below). Bilateral open testicular biopsy under local anesthesia for quantitative analysis was done by counting at least 10 seminiferous tubules on each side. Thus, a total of 20 or more tubules were included in the biopsy evaluation of each patient. Only mature spermatids were counted $\left(\mathrm{Sc}+\mathrm{Sd}_{1}+\right.$ $\mathrm{Sd}_{2}$ ) - putting in more simple terms - the elongated oval spermatids with dark, densely stained chromatin. So, the number of mature spermatids in a minimum of 20 tubules was totaled and divided that by the number of tubules $^{(4)}$. The number of mature spermatids per tubule correlated very closely to the sperm count per milliliter ${ }^{(4)}$. The equation given was $\mathrm{y}=\mathrm{a}(\mathrm{x})^{\mathrm{b}}$ where $\mathrm{x}$ is the expected sperm count in million $/ \mathrm{ml}$, $\mathrm{a}$ and $\mathrm{b}$ are two constants equal to 10.39 and 0.31 respectively and $\mathrm{y}$ is the number of late spermatids/tubule $^{(4)}$. So, $x=(y / a)^{1 / b}$. By this method, cases of partial obstruction can be diagnosed if there is a high discrepancy between the late spermatid score and the sperm count ${ }^{(4)}$. The concentration of seminal IGF-1 was determined in the patients by a specific enzyme immunoassay (IGF-1 ELISA kits from Mediagnost, Tubingen, Germany) in microtitre plates after acidethanol precipitation to remove the IGF-1 binding proteins ${ }^{(6)}$. The concentration of seminal $\alpha_{2}$-macroglobulin was determined in each patient by a specific enzyme immunoassay ( $\alpha_{2}$-macroglobulin ELISA kits from BIOMAC, Leipzig, Germany ${ }^{(6)}$.

\section{RESULTS:}

According to the scoring of testicular biopsies in relation to the actual sperm count in semen, the patients can be divided into 2 groups; 
Group I: Patients with likely partial or unilateral obstruction.

Group II: Patients with unlikely partial or unilateral obstruction.

No statistically significant differences were found between both groups as regards personal and medical characteristics, clinical examination, hormonal profile and actual sperm count $(\mathrm{P}>0.05)$. There was a highly statistically significant difference between both groups as regards the quantitative analysis of the testis biopsy ( $\mathrm{P}<0.001)$. There is no statistically significant difference between IGF-1 and $\alpha_{2}$ macroglobulins expected sperm count as well as actual sperm count.

\section{DISCUSSION:}

In this work, there is a lack of correlation between IGF- I \& $\alpha_{2}$-macroglobulin and expected sperm count in both groups. This can be possibly because both markers do not correlate with the state of spermatogenesis as well as the rate of passage of these markers through the male genital system may be affected by the partial obstruction. In this study, lack of correlation between IGF-1 \& $\alpha_{2}$-macroglobulin and actual sperm count is also present possibly as these markers do not correlate with the state of spermatogenesis. In this work, there is no correlation between the actual sperm count and testicular volumes in both groups.

\section{Conclusion:}

Due to lack of correlation between IGF$1 \& \alpha_{2}$-macroglobulin and the expected sperm count, we cannot rely on these markers as an alternative method for quantitative testicular biopsy for the diagnosis of obstructive oligozoospermia.

\section{REFERENCES:}

1. Belmonte I.G., Nistal M and De Serrano M (1998): Partial obstruction of the seminal path, a frequent cause of oligozoospermia in men. Hum. Reprod., 13 (12); 3402-3405.

2. Jequier A.M., Crich J.P. and Holmes S.C. (1983): Incomplete obstruction of the male genital tract: a cause of oligozoospermia. Br. J. Urol., 55, 545-552.

3. Hendry WF, Parslow JM and Sterdronska J. (1983): Exploratory scrotomy in 168 azoospermic males. Br. J. Urol., 55; 785 791.

4. Silber SJ and Rodriguez-Rigau LJ. (1981): Quantitative analysis of testicular biopsy: determination of partial obstruction and prediction of sperm count after surgery for obstruction. Fertil. Steril., 36, 480-485.

5. Schoysman R and Steward BH. (1980): Epididymal causes of male infertility. Monographs in Urology; 1(1), 1-3.

6. Glander HJ, Kratzsch J, Weisbrich $\mathrm{CH}$ and Birkenmeier G (1996): Insulin-like growth factor-1 and $\alpha 2$-macroglobulin in seminal plasma correlate with semen quality. Hum. Reprod. (11); 2454-2460.

7. Ritzen EM (1983): Chemical messengers between sertoli cells and neighboring cells. J Steroid Biochem., 19, 499-504.

8. Stahler MS, Cheng CY and Morris PL (1991): $\alpha 2$ macroglobulin: a multifunctional protein of the seminiferous tubule. Ann. NY Acad. Sci, 626, 73-80.

9. Nelson WO (1953): Interpretation of testicular biopsy. JAMA 151; 1449; Mannion RA, Cottrell TLC (1961): Correlation between testicular biopsy and sperm count. J Urol 85; 953-55

10. Albert A (1961): The mammalian testis. In Sex and Internal Secretions 1; 305-365. 


\section{تقييم مستوي عامل النمو شبيه الانسولين ا و الفا ץ ماكروجلوبيولين في السائل المنوي في توقع انتاجية الحيوانات المنوية المانية}

$$
\text { أ.د أحمد إبر اهيم رشيد و.د نيرمين سامي عبد الفتاحو .د دينا السيد الثناوي و ط أحمد سيد يوسف علي }
$$

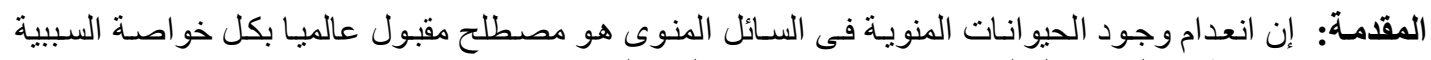

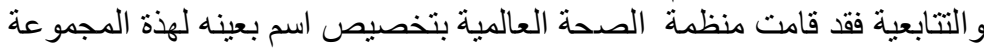

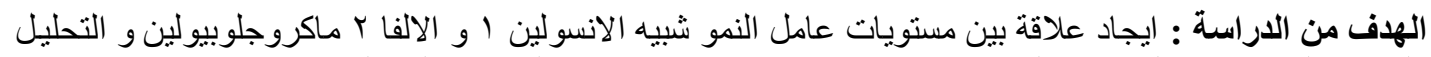

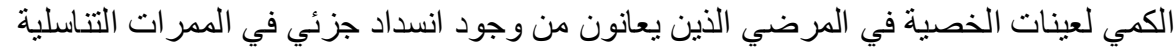

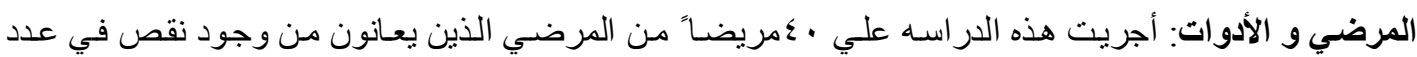

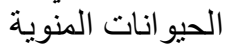

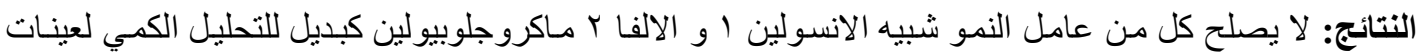
الخصية في المرضي الذين يعانون من وجود انسداد جزئي في الممر ات التين التناسلية. 